IRSTI 29.19.17

\title{
Analysis and identification of platinum-containing nanoproducts of plasma-chemical synthesis in a gaseous medium
}

\author{
D.V. Schur*, An.D. Zolotarenko, Al.D. Zolotarenko, O.P. Zolotarenko, M.V. Chimbai, \\ A.D. Zolotarenko, N.Y.Akhanova and M. Sultangazina \\ 'Institute of Problems of Materials Science, National Academy of Sciences of Ukraine, \\ 3, Krzhizhanovskogo str., 03142, Kiev, Ukraine \\ *e-mail:dmitry.schur@gmail.com
}

\begin{abstract}
This article studies a nanoproduct that is formed by simultaneous plasma-chemical evaporation of graphite and platinum. It was shown that the resulting deposits under different synthesis conditions have a similar and well-defined structure and consist of two main parts (core and enclosing bark). The structure of both parts is investigated at the micro- and nanoscale levels. The products of synthesis and similar products obtained without the use of platinum has been compared. The distribution of platinum in synthesis products is studied. It is proved that the atoms of the platinum catalyst influence the process of formation of the deposit. Namely, it stimulates the formation of a deposit where the deposit core containing platinumcontaining bundles of CNT exists as an independent core that does not have a strong connection with the deposit shell. It is found that differential-thermal analysis of CNM in air by the methods of TG, DTG, DTA allows to reveal insignificant differences in the heat resistance of different carbon nanostructures, and thus it can be used for their identification. Such studies are of great importance for the synthesis of platinumcontaining catalysts for fuel cells and other chemical industries.
\end{abstract}

Key words: plasma-chemical synthesis, platinum nanostructures, deposit, CNTs.

PACS numbers: 61.48.De, 52.40.Hf.

\section{Introduction}

Platinum-containing carbon nanostructures can now be used not only in the design of fuel cells, but also allows in finding solutions to the problem of effective hydrogen storage [1]. It is possible that in the future the fullerit-metal-hydrogen system can boldly compete with modern advanced structures for storage of hydrogen - the environmentally clean energy source [2-6].

To date, the synthesis of CNTs as well as the CNM is carried out by different methods: laser action on metal-graphite electrodes; plasmachemical evaporation of graphite in a gas [7-14] and liquid medium in the presence of catalysts [15-24]; pyrolysis of hydrocarbon structures on catalysts; pyrolysis of benzene in the presence of organometallic compounds (ferrocene and metal phthalocyanides); the dissolution of carbon monoxide on catalysts.

The method of plasma-chemical evaporation of graphite in an inert gas environment is relatively common, productive and quite effective due to the fact that it allows to obtain both soluble [25-26] and insoluble CNM [27-28]. But only the plasmachemical evaporation of the anode in a gas medium can guarantee the synthesis of fullerene particles. In this case, the method makes it possible to easily change the synthesis modes, use a different gas medium and, most importantly, achieve a high yield of CNM with different structure and morphology.

However, for today, the oxidation of the CNM deposit (products formed on the cathode) obtained by the plasma chemical method in the gaseous medium which allow the identification of new nanofibers of carbon has not been studied enough.

\section{Experimental}

To obtain platinum-containing nanoproducts, a plasma chemical plant was used to evaporate the electrodes in a gaseous medium (Figure 1). During the synthesis, electrodes made of high-grade graphite of the PGM-7 grade were used. Also, hollow graphite electrodes containing platinum were used which was 
evaporated in a plasma at a pressure of $0.02-0.09 \mathrm{MPa}$ in an inert helium medium.

In a vertical reactor the consumable anode electrode remained stationary and the nonconsumable cathode electrode moved along the axis of the reactor. Thus, a uniform distribution of soot over the entire surface of the reactor walls was observed, and relatively the same thermodynamic conditions were obtained for the condensation of the synthesis products.
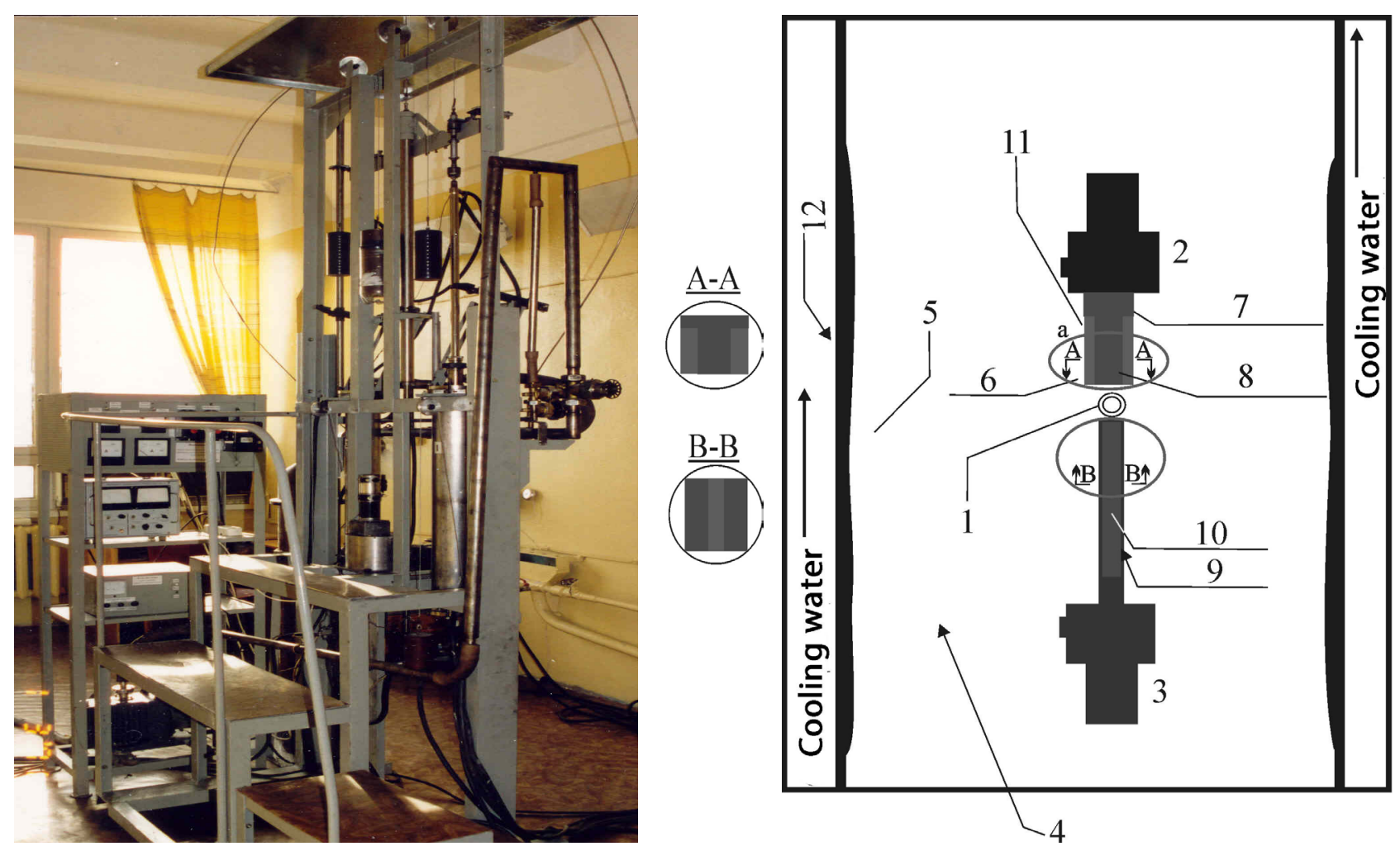

Figure 1 - General view of the set up, diagram of a cylindrical reactor for plasma-chemical synthesis of nanostructures in a gaseous medium: 1 - plasma; 2 - cathode; 3 -anode; 4 - helium-containing medium; 5 - platinum-containing carbon black; 6 - deposit; 7 - non-consumable electrode; 8 - the core of the deposit containing MNT; 9 - consumable electrode; 10 - wire catalyst fixed with graphite dust; 11 - the external layer of the deposit; 12 - reactor wall.

A hollow graphite anode containing platinum in the form of a wire was used to introduce the platinum catalyst into the plasma-chemical synthesis zone, the catalyst in the anode cavity was fixed with graphite dust. The cavity of the anode electrode is located along the axis of the atomized part of the anode (Figure 2).

In a number of plasma-chemical syntheses, the anode was evaporated from pure graphite, and also the anode doped with a platinum catalyst (Table 1 ). The time of plasma-chemical synthesis in the presence of a platinum catalyst lasted more by 40 minutes, considering that the length of the anode doped with platinum $(18 \mathrm{~cm})$ was less than the length of a pure graphite anode $(21.1 \mathrm{~cm})$. In addition, the evaporation of the platinum platinum-containing electrode was accompanied by fluctuations in the current (175-
$225 \mathrm{~A})$ and $35-37 \mathrm{~V}$, while the evaporation of the graphite anode was relatively quiet (current strength 185-200 A, voltage 30-33 V). This effect can be explained by the higher evaporation temperature of the platinum-containing anode.

At the end of the evaporation of the platinumcontaining anode, the mass of the synthesis product (Deposit and Wall soot) exceeds the mass of the product multiple times when the graphite anode evaporates, both along the wall soot and along the mass of the deposit. The large mass of Wall soot suggests that in the process of plasma-chemical synthesis, most of the platinum atoms in the process of synthesis of CNM move to the zone of lower pressures and temperatures, namely toward the periphery of the synthesis zone until they cool down on the reactor wall. 


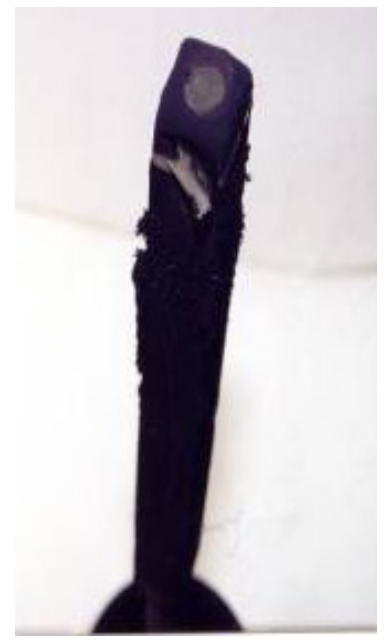

Figure 2 - Anode which contains platinum and carbon dust.

\section{Results and Discussion}

The length $(5 \mathrm{~cm})$ and therefore the mass $(44.990 \mathrm{~g})$ of the platinum deposit significantly exceeds the parameters of the deposit obtained by evaporation of the graphite electrode (length $2.1 \mathrm{~cm}$, weight $7.5 \mathrm{~g}$ )

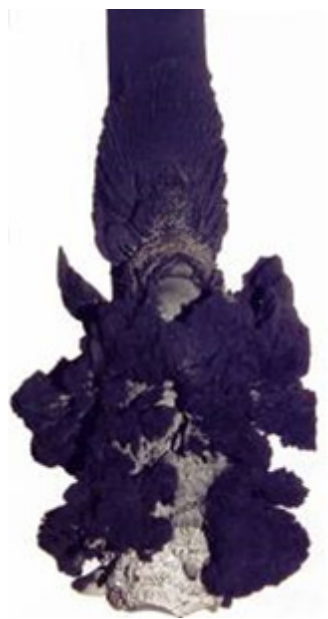

Figure 3 - Appearance of the platinumcontaining deposit on the cathode.

(Table 1). This suggests that the atoms of platinum reorganize carbon atoms in the process of plasmachemical synthesis which makes it possible to accelerate the formation of ONS having resistance to plasma precursor temperatures, and also having sufficient electrical conductivity to form an electric arc.

Table 1 - Conditions and results of plasma-chemical synthesis

\begin{tabular}{|c|c|c|c|}
\hline \multirow{4}{*}{} & & Graphite (C) & C-Pt \\
\cline { 2 - 4 } & The anode contains & Only graphite & Graphite and Pt \\
\cline { 2 - 4 } & Length of cathode & $8.4 \mathrm{~cm}$ & $8.4 \mathrm{~cm}$ \\
\cline { 2 - 4 } & Length of anode & $21.1 \mathrm{~cm}$ & $18 \mathrm{~cm}$ \\
\cline { 2 - 4 } & Catalyst (length * width) & - & $11^{*} 0.1 \mathrm{~cm}$ \\
\cline { 2 - 4 } & Current strength & $185-200 \mathrm{~A}$ & $175-225 \mathrm{~A}$ \\
\cline { 2 - 4 } & Voltage & $30-33 \mathrm{~V}$ & $35-37 \mathrm{~V}$ \\
\cline { 2 - 4 } & Vacuum gauge & $0.190-0.174 \mathrm{~atm}$ & $0.70-0.13-0.33 \mathrm{~atm}$ \\
\cline { 2 - 4 } & Temperature of cooled reactor jacket & $31{ }^{\circ} \mathrm{C}$ & $25^{\circ} \mathrm{C}$ \\
\cline { 2 - 4 } & The synthesis medium & Helium & Helium \\
\cline { 2 - 4 } & Soot & $10.400 \mathrm{~g}$ & $24.690 \mathrm{~g}$ \\
\cline { 2 - 4 } & Deposit & $7.500 \mathrm{~g}$ & $44.990 \mathrm{~g}$ \\
\cline { 2 - 4 } & Chips & $4.700 \mathrm{~g}$ & $8.495 \mathrm{~g}$ \\
\cline { 2 - 4 } & Anode Remainder & $6.6 \mathrm{~cm}$ & $1.8 \mathrm{~cm}$ \\
\cline { 2 - 4 } & Length of deposit & $2.1 \mathrm{~cm}$ & $5 \mathrm{~cm}$ \\
\cline { 2 - 4 } & Synthesis time & $120 \mathrm{minutes}$ & $160 \mathrm{minutes}$ \\
\hline
\end{tabular}




\section{Deposit}

In the course of synthesis, when a platinumcontaining anode was evaporated on a nonconsumable electrode (cathode), a build-up called a deposit was formed during the synthesis (Figure 3). The deposit consists of two parts: a loose core formed by multiwalled nanotubes (MNTs) having a minimum number of structural defects (Figure 4), and a strong crust formed by layered graphite-like structures containing in their volume a smaller amount of MNT.

The shell (crust) of the deposit formed, as in the case of syntheses in the presence of other catalysts, consisted of layered structures located perpendicular to the deposit axis (Fig. 5), densely packed in a single structure.

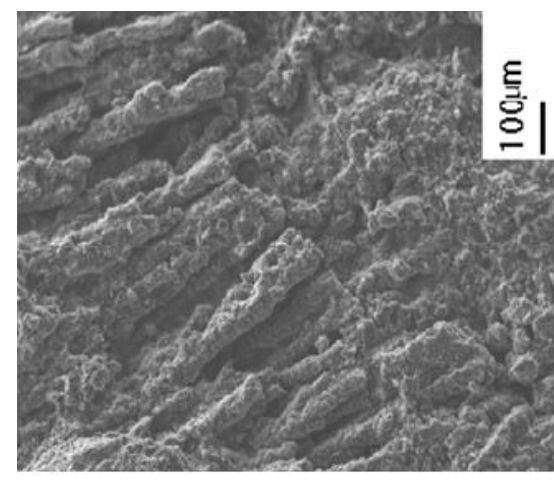

(a)

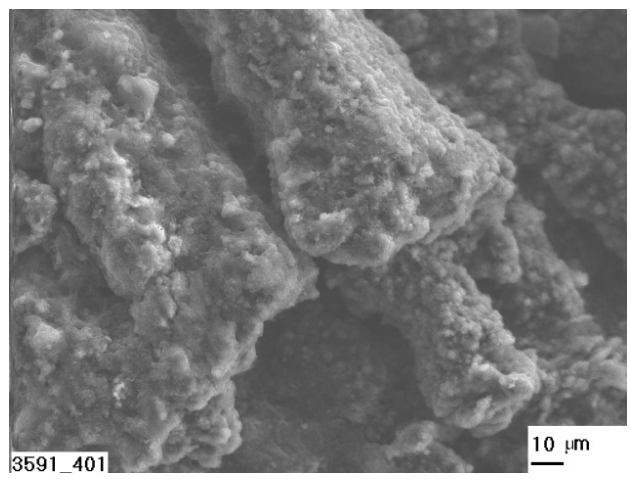

(b)

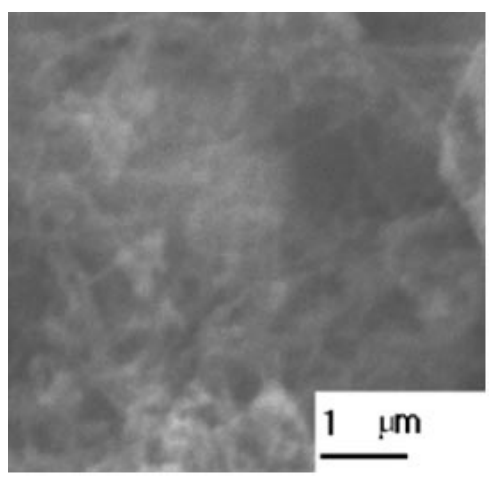

(c)

Figure 4 - Loose-core deposit core: (a) - general view of core conglomerates; (b) - a conglomerate consisting of bundles of NT; (c) - bundles of nanotubes constituting conglomerates.

The core is porous and loose (Figure 4 (a)), a deposit consisting of conglomerates (Figure 4 (b)) oriented along the deposit axis and formed of carbon- like carbon nanotubes (Fig. 4 (c)). The bundle-like structures are joined by multiwalled carbon nanotubes in diameter from 4 to $25 \mathrm{~nm}$ (Figure 6).
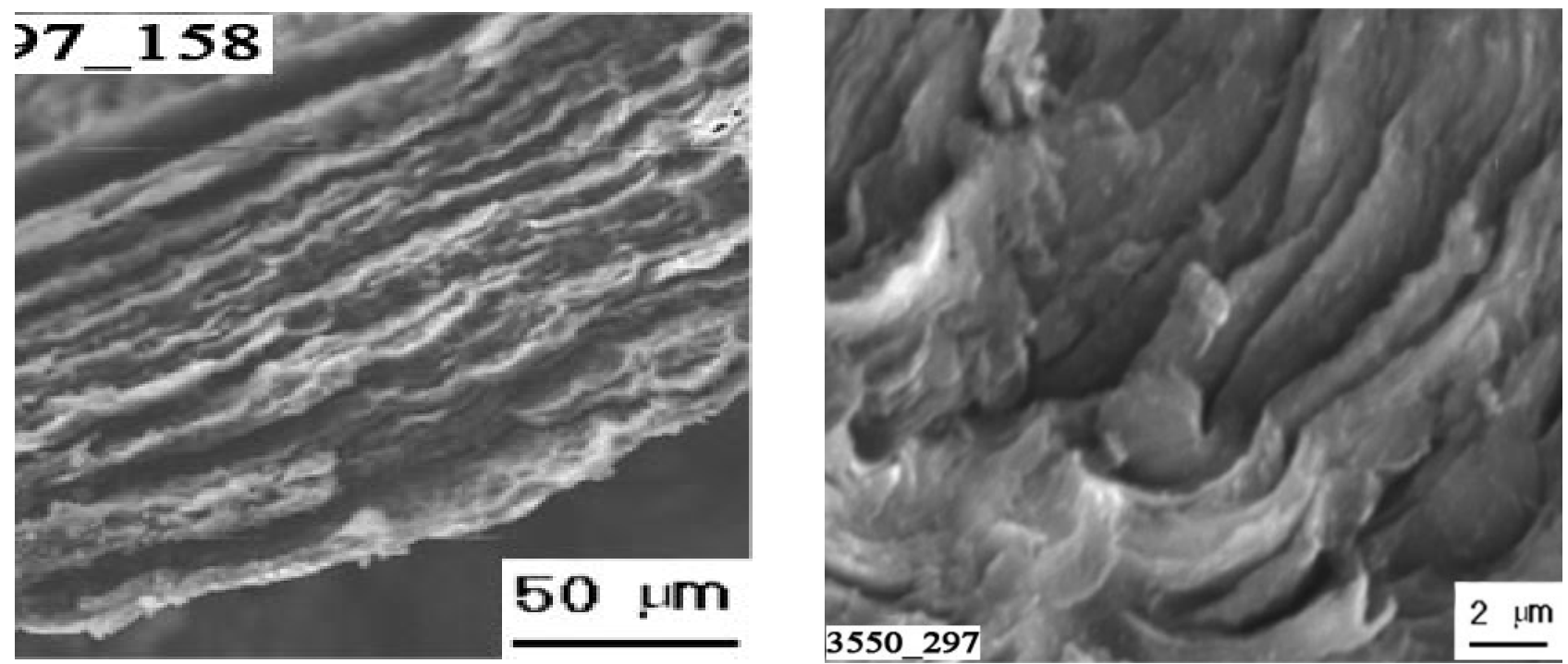

Figure 5 - Dense crust of deposit, formed by layered graphite-like structures. 


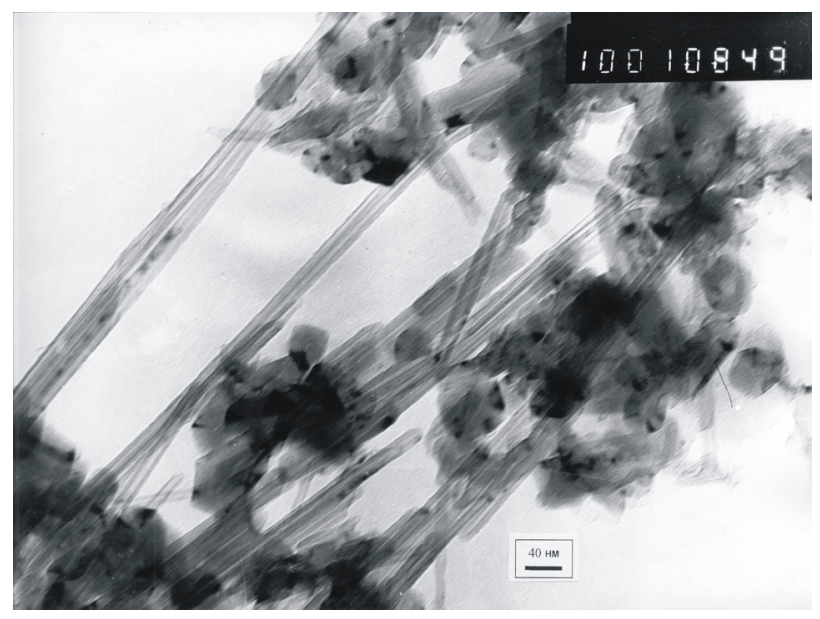

Figure 6 - Carbon nanotubes constituting the core of the deposit, obtained by the simultaneous evaporation of a graphite electrode doped with platinum.

Upon evaporation of a graphite electrode doped with platinum, a core is formed which has a much denser structure than that obtained by a non-catalytic method. Forming columnar structures are oriented parallel to the deposit axis and have a diameter of $100-150 \mu \mathrm{m}$ (Figure 7 (a), (b), (c)). They are also formed from beam-like carbon nanotubes (CNTs) (Figure 6), in diameter 4-25 nm.

In the plasma-chemical synthesis of platinumcontaining carbon nanostructures, not only hollow carbon nanotubes (CNTs) are formed, but also tubes having various structural anomalies. Nanotubes have a rougher outer surface and some inclusions. As shown by the X-ray microanalysis in the core, the content of platinum turned out to be negligible, reaching hundredths of a percent. X-ray diffraction analysis also recorded hexagonal graphite with an admixture of the rhombohedral phase in all parts of the deposit (core and shell).

However, studies of the platinum-containing deposit showed that, unlike similar plasma-chemical syntheses in the gaseous medium, the core of the platinum-containing deposit is well separated from the deposit shell (bark) mechanically and can exist as a single rod.

Thus, a platinum catalyst in plasma-chemical synthesis in a gaseous medium allows the creation of centimeter rods made of beam-like carbon nanotubes (CNTs) that withstand super high temperatures (12000 K) [29].

The possibility of separating the deposit core, consisting of bundles of CNTs, from the deposit crust allows us to consider depositary parts (core and core) as independent products of plasma-chemical synthesis. Moreover, the possibility of separating deposited CNTs from graphite-like bark increases the purity of deposit CNTs and consequently reduces their cost price. Since earlier deposits were crushed to separate the ONS from graphite-like structures. A platinum-containing graphite -like bark (shell) can be used to produce graphite already enriched with platinum.

Platinum-containing CNTs and graphite-like structures, as the final product of processing a platinum-containing deposit, can be key elements of fuel cells which is relevant to this day. Platinumcontaining CNTs and graphite-like structures, as the final product of processing a platinum-containing deposit, can be key elements of fuel cells which is relevant to this day.

Thus, it should be noted that during the evaporation of a graphite electrode doped with platinum in an electric arc in an inert helium medium, the bulk of the metal participates in all plasma-chemical reactions and is redistributed among different products.

Most of it moves in the flow of condensate to the walls of the reactor. According to the emission spectral analysis, the largest amount of platinum is in the wall soot (more than $1 \%$ by mass). A small fraction of platinum is less than $1 \mathrm{wt} . \%$ In the cationic state, under the influence of a strong electric field, together with the carbon vapor moves to the cathode, forming a platinum-containing deposit. Despite the high temperature in the deposit formation zone which exceeds the boiling point of platinum $\left(3800^{\circ} \mathrm{C}\right)$, platinum was present in the deposit. 


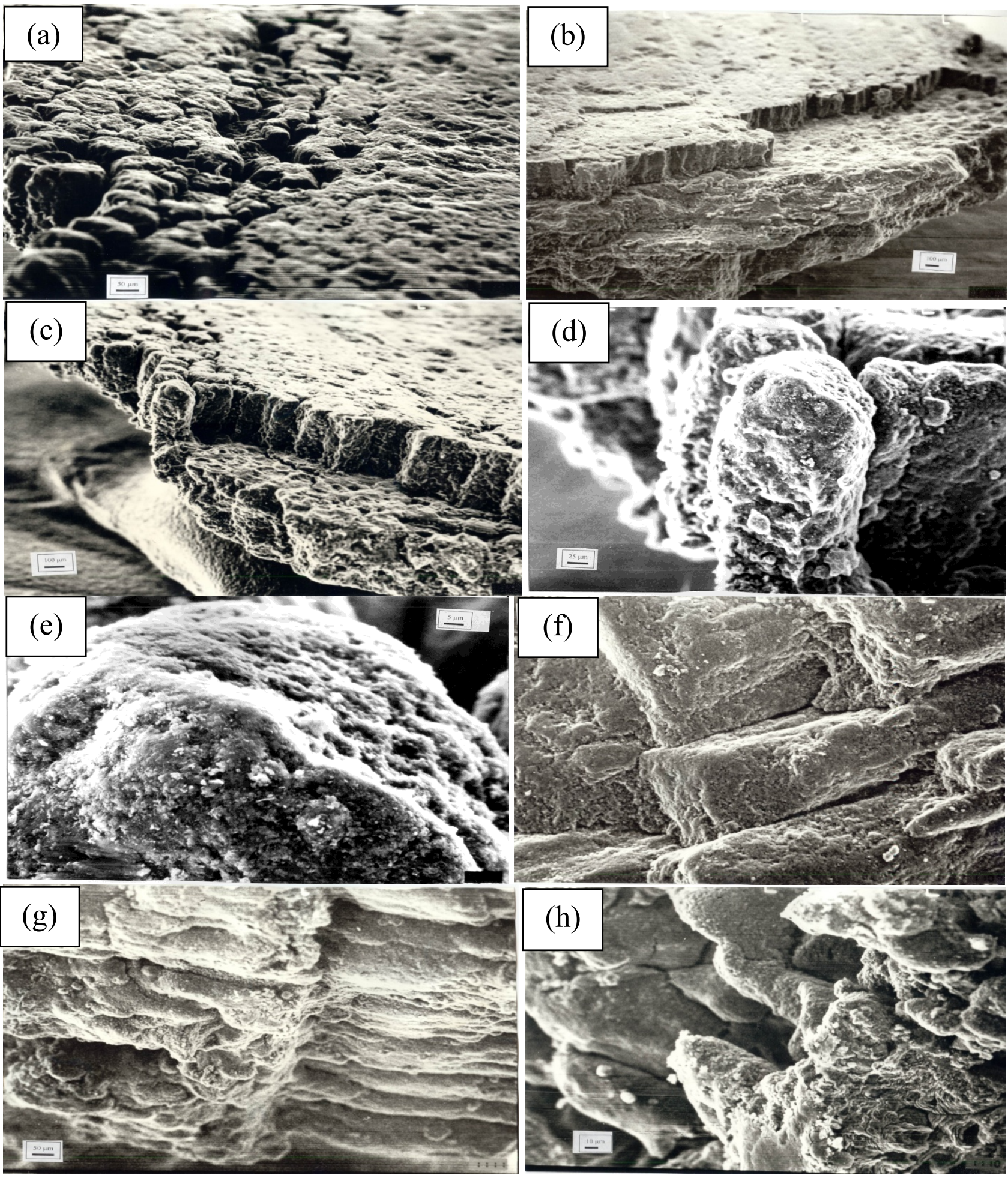

Figure 7 - Morphology of the core of a platinum-containing deposit (SEM) formed by the

simultaneous evaporation of a graphite electrode doped with platinum: (a), (b), (c), (d) - core blocks; (e) - block morphology; (g) - is the boundary between the shell and the core; (f), (h) - are the structures of the boundary layer. 
As a result of studying the chemical composition of the parts of the platinum-containing deposit, it was determined that the Pt atoms in the deposit are distributed unevenly. Most of the deposit Pt is less than $1 \%$ concentrated in the bark of the deposit itself. We believe that in the case of an electric arc, the flow of electrons passing through the forming deposit that heats it not only affects the formation of the structure of the carbon part of the deposit, but also exerts various processes for the separation of platinum atoms. It settles only in the low-temperature part which is the crust of the deposit.

The presence of platinum explains the higher thermal stability of the platinum deposit crust. Differential-thermal analysis (DTA), thermogravimetric (TG) and differential thermogravimetric (DTG) analyzes confirm these findings. Thus, the temperature at which the platinumcontaining bark begins to interact with oxygen in the air $\left(680^{\circ} \mathrm{C}\right)($ Table 2 , item 2$)$ exceeds the temperature of interaction with the pure carbon bark $\left(\mathrm{T} .=575^{\circ} \mathrm{C}\right)$ (Table 2, item 1) (Figure 8 (a), (b)).

The DTA curve (Figure 8 (b)) marks the biphasic nature of the deposit crust containing platinum. Apparently, in addition to the graphitelike component, this sample contained multi-walled nanotubes, the growth of which initiated the presence of platinum in the cortex.

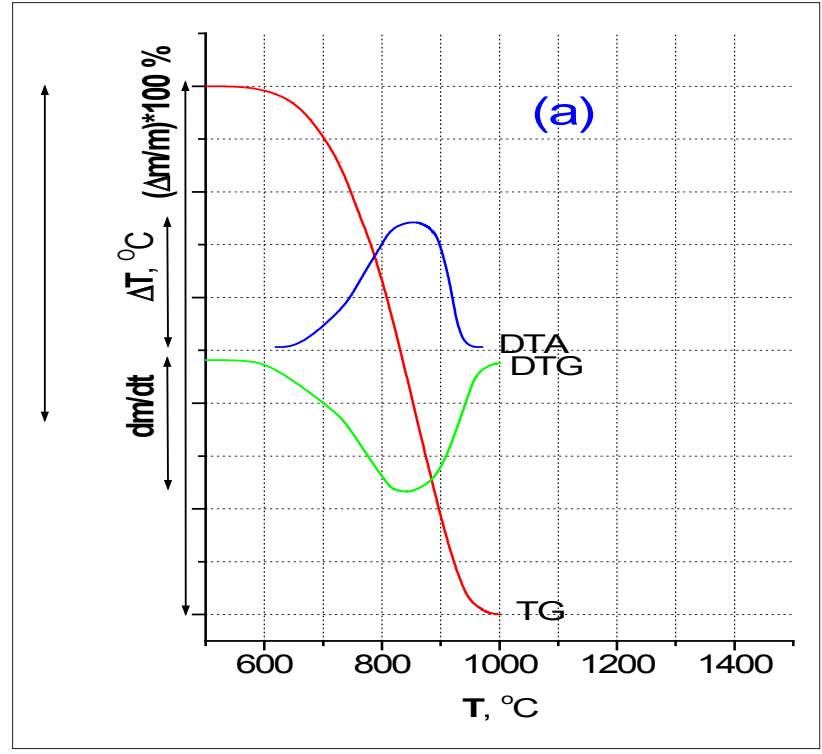

a)

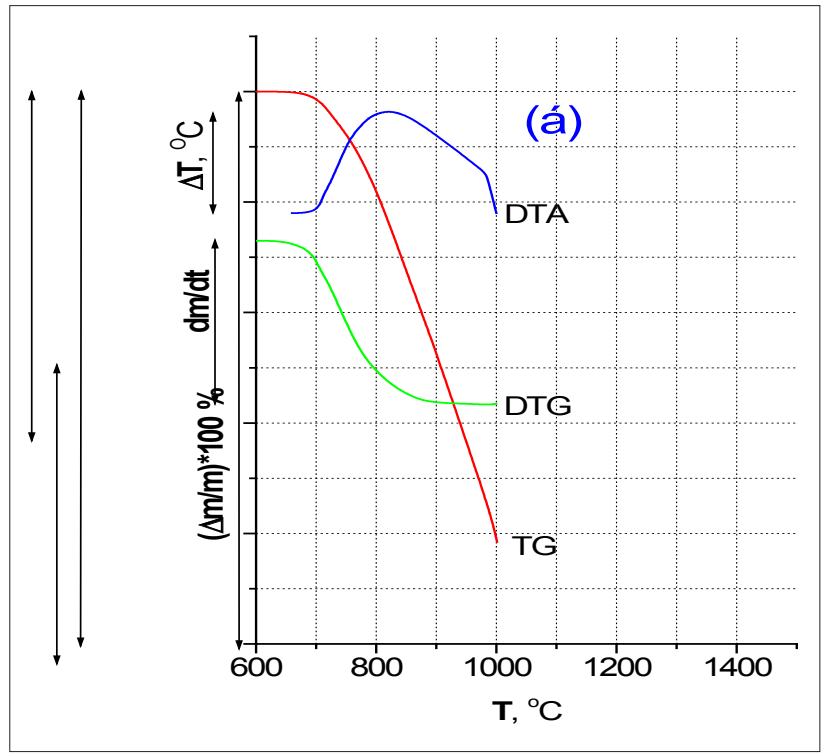

b)

Figure 8 - Investigation of the thermal stability of the shell of deposits of plasma-chemical synthesis in a gaseous medium: (a) - the crust of the deposit, obtained during the uncatalyzed synthesis;

(b) - the bark of the deposit containing Pt.

Table 2 - Thermal stability of parts of platinum-containing deposits of plasma-chemical synthesis in a gaseous medium.

\begin{tabular}{|c|c|c|c|c|c|}
\hline \multirow{2}{*}{ № } & \multirow{2}{*}{ Material } & \multirow{2}{*}{$\begin{array}{c}\text { Interaction interval, } \\
{ }^{\circ} \mathrm{C}\end{array}$} & DTG & \multicolumn{2}{|c|}{ DTA } \\
\hline & & & $\mathrm{T}_{1 \max },{ }^{\circ} \mathrm{C}$ & $\mathrm{T}_{1 \max },{ }^{\circ} \mathrm{C}$ & $\mathrm{T}_{2 \max },{ }^{\circ} \mathrm{C}$ \\
\hline 1 & Shell without catalyst & $575-980$ & 840 & 840 & \\
\hline 2 & Shell with catalyst $(\mathrm{Pt})$ & $680->1000$ & 865 & 825 & 990 \\
\hline 3 & Core with catalyst $(\mathrm{Pt})$ & $690-965$ & 865 & 800 & 910 \\
\hline 4 & Core without catalyst & $575-990$ & 870 & 850 & 960 \\
\hline
\end{tabular}


The core of the deposit formed from carbon-like carbon nanotubes where a scanty platinum content is found also shows a higher thermal stability than the core of the deposit obtained from uncatalculated plasma-chemical synthesis in a gas medium $\left(575^{\circ} \mathrm{C}\right)$. The beginning of the reaction with oxygen of air is $690^{\circ} \mathrm{C}$

Thermal analysis showed that in the core of the deposit synthesized in the presence of a platinum catalyst, there are two phases that react with air oxygen at $800^{\circ} \mathrm{C}$ and $910^{\circ} \mathrm{C}$ (Table 2 ).

\section{Wall-mounted soot}

A mixture of condensate formed on the walls of the reactor and in the gas phase forms a walled carbon black. It contains both a fullerene-like and an insoluble fraction in liquid hydrocarbons.

At the micro level, the layer of walled soot has the structure shown in Figure 9. The layer of wall soot was previously subjected to sonication in alcohol. The nanostructures that make up it have different geometric shapes and structures (Figure 10).

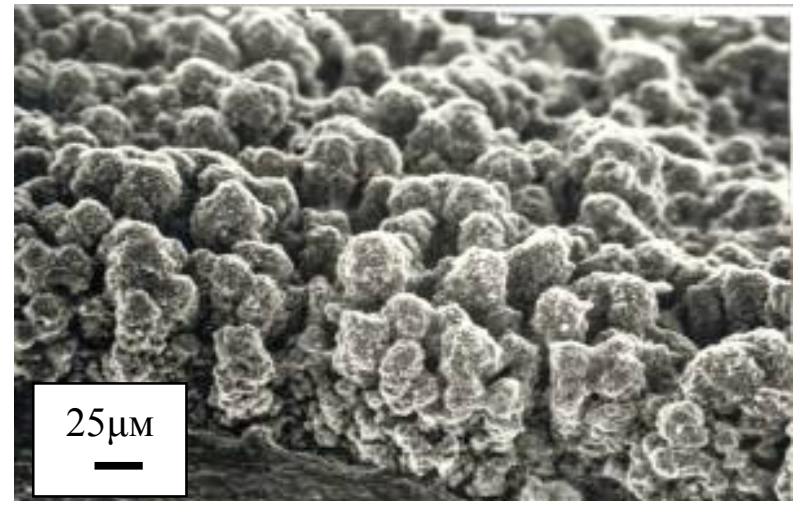

(a)

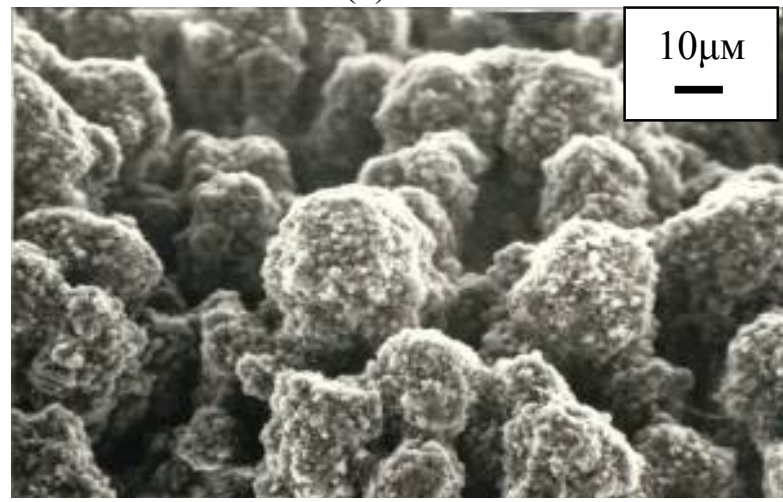

(c)

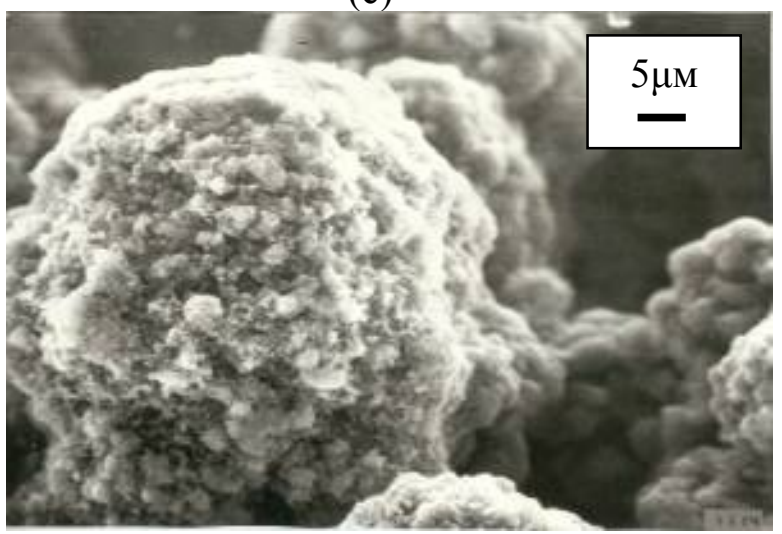

(e)

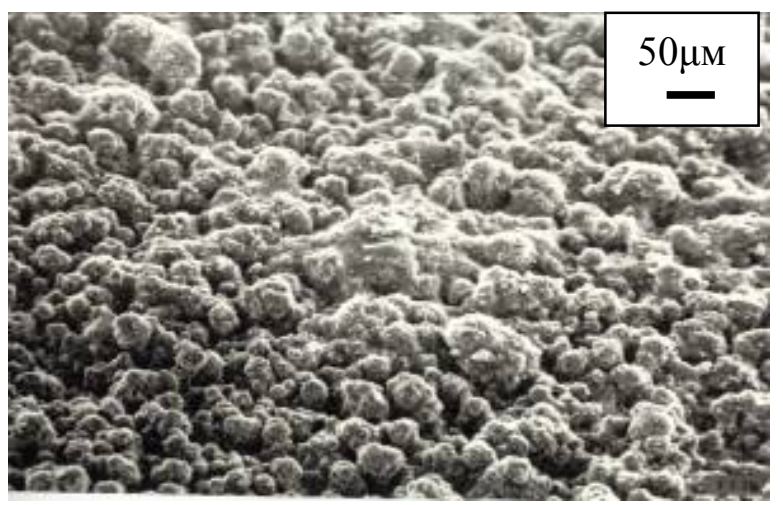

(b)

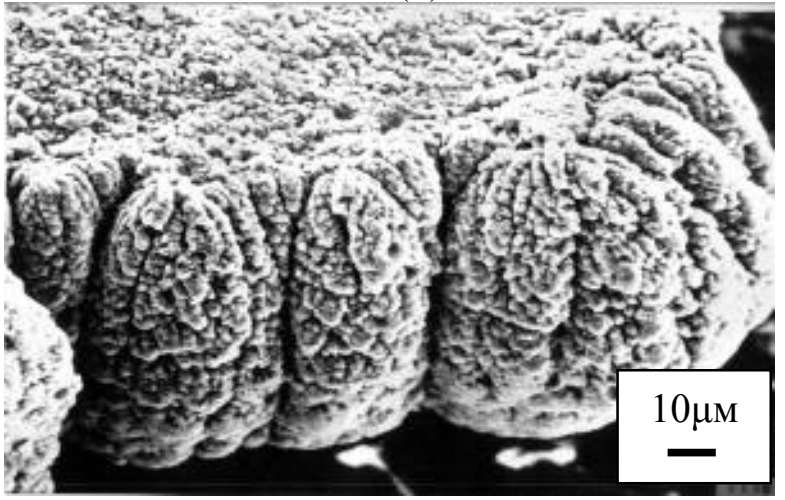

(d)

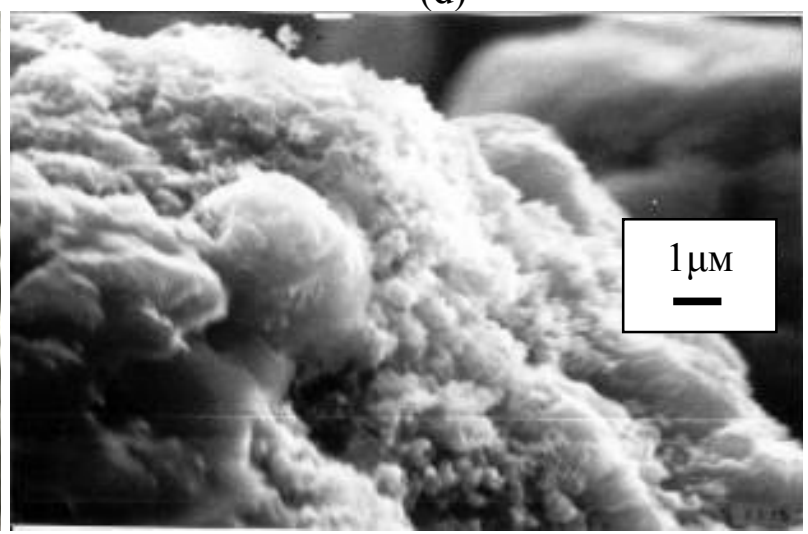

(f)

Figure 9 - Wall-mounted soot. Surface morphology after ultrasound treatment in ethanol: ((a), (b), (c), (d), (e), (f) - SEM photo with varying degrees of magnification). 

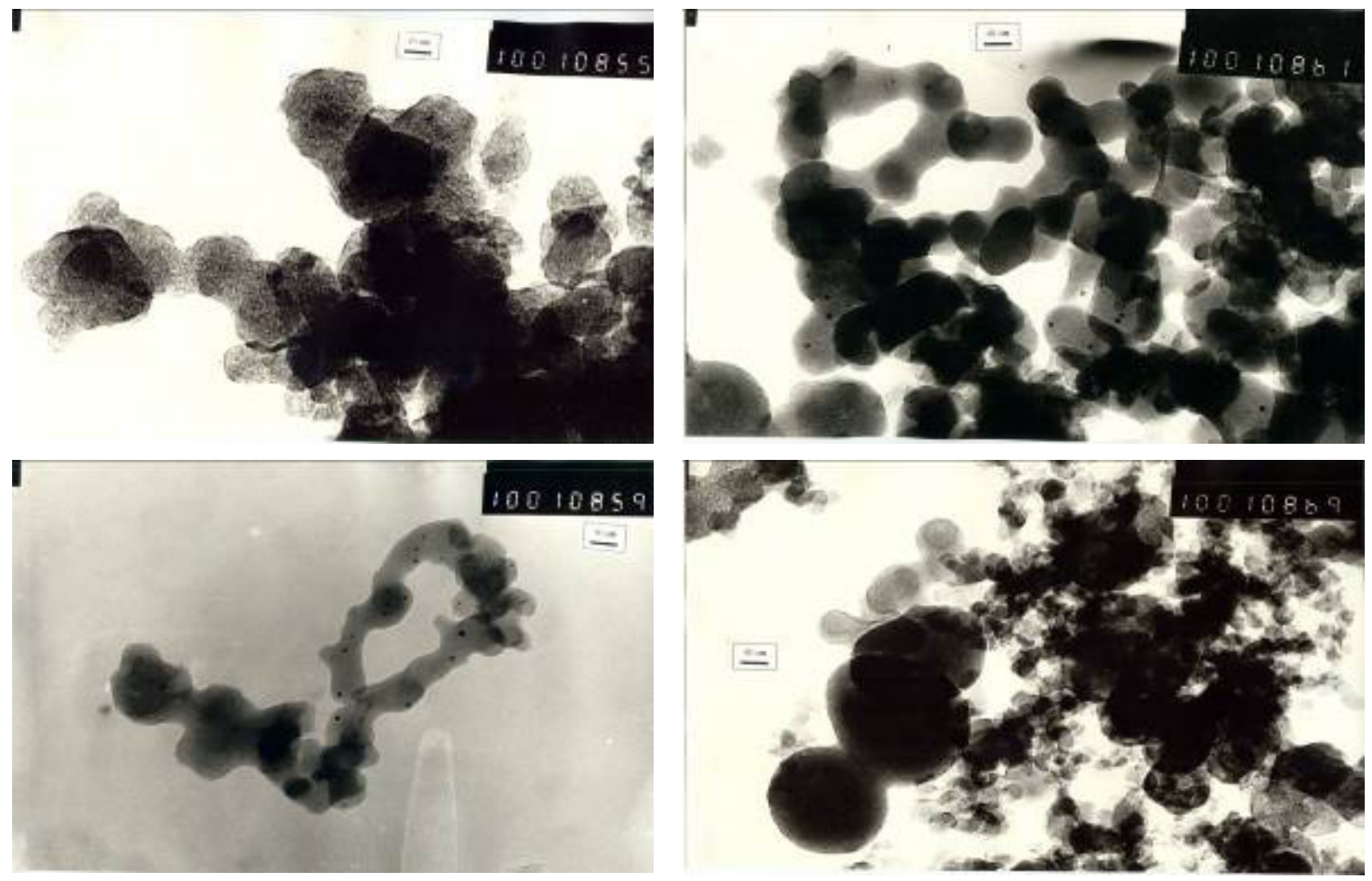

Figure 10 - Photographs of nanoscale particles composing platinum-containing wall soot (TEM).

\section{Conclusions}

When analyzing the chemical composition of the platinum-containing deposit, it turned out that the Pt atoms in the deposit structure are distributed unevenly. The central part of the deposit (the core) contains trace amounts of platinum that is confirmed by the results of emission spectral analysis and by the X-ray microanalyzer of the core shear surface. The bulk of the platinum in the deposit focuses on the deposit shell. We believe that a large flow of electrons passing through the emerging deposit and plasma temperatures have a significant effect on the formation of the deposit structure as well as the separating effect on the atoms, molecules and particles that make up the synthesis zone.
It is proved that the atoms of the platinum catalyst influence the process of formation of the deposit. Namely, it stimulates the formation of a deposit where the deposit core containing platinumcontaining bundles of CNT exists as an independent core that does not have a strong connection with the deposit crust. The possibility of separating the deposit core consisting of bundles of CNTs from the deposit crust allows one to consider depository parts (core and shell) to be independent products of plasma-chemical synthesis.

It is established that differential-thermal analysis of CNM in air by the methods of TG, DTG, DTA allows to reveal insignificant differences in the heat resistance of different carbon nanostructures, and therefore, it can be used for their identification.

\section{References}

1. D.V. Shchur, Z.A. Matysina, S.Yu. Zaginaychenko. Carbon nanomaterials and phase transformations in them: Monograph. - Dnipropetrovsk: Science and Education, 2007. P - 680 (in Russian).

2. D.V. Schur, A.A. Lyashenko, V.M. Adejev, V.B. Voitovich, S. Yu. Zaginaichenko. .Niobium as a construction material for a hydrogen energy system. // International journal of hydrogen energy. -1995. -Vol. 20 (5). - Pp.405-407. 
3. Z.A. Matysina, S.Y. Zaginaichenko, D.V. Schur. Hydrogen solubility in alloys under pressure // Int. J. Hydrogen Energy. -1996,. -Vol. 21. - No. 11/12. -Pp. 1085-1089.

4. Y.M. Lytvynenko, D.V. Schur. Utilization the concentrated solar energy for process of deformation of sheet metal / // Renewable energy. - 1999. -Vol.16 (1-4). - Pp. 753-756.

5. An. D. Zolotarenko, Z.A. Matysina, S. Yu. Zaginaichenko, D.V. Schur, A. Veziroglu, T.N. Veziroglu, M.T. Gabdullin, N.F. Javadov, Al. D. Zolotarenko. Hydrogen in Crystals. Monograph.- Kiev Publishing house "KIM", Kiev, - 2017. 1061 p. (in Russian).

6. Z.A. Matysina, S. Y. Zaginaychenko, D. V. Schur, An. D. Zolotarenko, Al. D. Zolotarenko, M. T. Gabdullin. Bilary and Potassium Alanates are promising Hydrogen accumulators. // International scientific Alternative Energy and Ecology magazine (ISJAEE). -2017. -No. 13-15. -Pp. 37-60.

7. S. Iijima. Helical microtubules of graphitic carbon //Nature. - 1991. -Vol. 354. - Pp. 56-58.

8. N. Sano, H. Wang, M. Chhowalla, I. Alexandrou, G. A. J. Amaratunga. Synthesis of carbon'onions' in water // Nature. - 2001. - Vol. 414. - P. 506.

9. Lange H. / Lange H., Sioda M., Huczko A., Zhu Y.Q., Kroto H.W., Walton D.R.M. Fullerenes and nanotubes: materials for the new chemical frontier // Carbon. - 2003. - Vol. 41. - P. 1617.

10. E. Tatarova, N. Bundaleska, J. Ph. Sarrette, C. M. Ferreira. Plasmas for environmental issues: from hydrogen production to 2D materials assembly // Plasma Sources Science and Technology. - 2014, - Vol. 23. - P. 063002.

11. An.D. Zolotarenko, Zolotarenko Al.D, Zolotarenko A.D, Voichuk G.A., Schur D.V., Zaginaychenko S.Yu. Synthesis of endofullerenes by an arc method deposit // Nanosystem, nanomaterials, nanotechnology. - 2005. - Vol. 3. - No. 4. - P. 1133-1144. (in Russian)

12. Al.D. Zolotarenko, An.D. Zolotarenko, V.A. Lavrenko, S.Yu. Zaginaichenko, N.A. Shvachko, O.V. Milto, V.B. Molodkin, A.E. Perekos, V.M. Nadutov, Yu. A. Tarasenko. Encapsulated ferromagnetic nanoparticles in carbon shells. Carbon Nanomaterials in Clean Energy Hydrogen Systems // NATO Science Series. The Netherlands. - 2011. P. 127-135.

13. E.I. Golovko, A.D. Zolotarenko, A.D. Zolotarenko, G.A. Vojchuk, A.D. Zolotarenko, V.M. Adeev, A.V. Kotko, A.J. Koval', S.A. Firstov, D.V. Schur, O.V. Mil'to, S.J. Zaginaychenko. Synthesis of platinum-containing Carbon Nanostructures // Proc. of 9th International Conference "Hydrogen Materials Science and Chemistry of Carbon Nanomaterials", Sevastopol, Crimea, Ukraine, September. 5-11. -2005. -Pp.1014-1016.

14. Yu.M. Shulga, D.V. Schur, S.A. Baskakov, A.P. Simanovskiy, A.A. Rogozinskaya, A.A. Rogozinskiy, A.P. Mukhachev. XRD Patterns of cathode deposits formed in electric arc sputtering Zr-Me-graphite electrodes // Proc. of NATO ARW "Hydrogen Materials Science and Chemistry of Carbon Nanomaterials. - Boston: Kluwer Academic Publishers. -2004. - Vol. 172. - Pp.137-142.

15. A. Huczko. Synthesis of aligned carbon nanotubes // Appl. Phys. A. - 2002. - Vol. 74. -P. 617-638.

16. A.D. Zolotarenko, A.D. Zolotarenko, A.D. Zolotarenko, G.A. Voichuk, A.D. Zolotarenko, V.M. Adeev, A.B. Korotko, A.Y. Koval, C.A. Firstov, D.V. Shchur, O.M. Milto, S.I. Zaginaychenko, E.I. Golovko. Synthesis of endofullerenes by the arc method deposit // The journal "Nanosestemi, nanomaterials, nanotechnologies. - 2005. ol.3, №4, C. 1133-1144 (in Russian);

17. D.V. Schur, A.G. Dubovoy, A.F. Savenko, S.Yu. Zaginaichenko. Method for synthesis of carbon nanotubes in the liquid phase // Abstracts of International Conference on Carbon "Carbon'04", Providence, Rhode Island, USA, July 11-16. -2004. - P. 187.

18. D. V. Schur, A. G. Dubovoy, S.Yu. Zaginaichenko, V. M. Adejev, A.V. Kotko, V.A. Bogolepov, A.F. Savenko, Al. D. Zolotarenko. Production of carbon nanostructures by arc synthesis in the liquid phase // Carbon. - 2007. - Vol. 45. -N.6. -Pp. 1322-1329.

19. N.S Koprinarov., M.A. Constantinova, G.V. Pchelarov, M.V. Marinov. Fullerene macro structures // Journal of Crystal Growth. - 1997, - Vol. 171, - P. 111.

20. / And. Zolotarenko, A.G. Dubovoy, A.E. Perekos, V.A. Lavrenko, T.V. Efimova, V.P. Zalutsky, T.V. Ruzhitskaya, A.V. Kotko, Al. Zolotarenko. The effect of the magnetic field on the phase-structure state and the magnetic properties of highly dispersed Fe powders obtained by electrospark dispersion // Journal of Nanosystems, Nanomaterials, Nanotechnologies. -2013. - Vol. 11. - No. 1.2. - P. 131-140.

21. Biro L.P., Z.E. Horvath, L. Szalmas, K. Kertesz, F. Weber, G. Juhasz, G. Radnoczi, J. Gyulai. Continuous carbon nanotube production in underwater AC electric arc // Chemical Physics Letters. - 2003. - Vol. 372, - P. $399-402$.

22. V.A. Lavrenko, I.A. Podchernyaeva, D.V. Shchur, An.D. Zolotarenko, Al.D. Zolotarenko. Features of physical and chemical adsorption during interaction of polycrystalline and nanocrystalline materials with gases // Springer US «Powder Metallurgy and Metal Ceramics», USA, January. - 2018. -Vol. 56. - Issue 9-10. -Pp. 504-511. 
23. Al.D. Zolotarenko, An. D. Zolotarenko, V.A. Lavrenko, S. Yu. Zaginaichenko, N.A. Shvachko, O.V. Milto, V.B. Molodkin, A.E. Perekos, V.M. Nadutov, Yu.A. Tarasenko. Encapsulated ferromagnetic nanoparticles in carbon shells // Springer «Carbon Nanomaterials in Clean Energy Hydrogen Systems», NATO Science Series. The Netherlands - 2011. - P. 127-135.

24. An. D. Zolotarenko. Physicochemical features of the synthesis of carbon nanoparticles in the arc phase in the rare phase // Abstract. dis. Cand. chem. Sciences: spec. 02.00.04 "Physical Chemistry" / // IPM of NAS of Ukraine. - Kiev, 16 herbs 2014. P. - 22 (in Russian).

25. N.S. Anikina, Z.S. Yu, M.I. Maistrenko, A.D. Zolotarenko, G.A. Sivak, D.V. Schur. Spectrophotometric analysis of C60 and C70 fullerences in the toluene solutions // Springer «Hydrogen Materials Science and Chemistry of Carbon Nanomaterials», NATO Science Series II. - 2005. -Vol. 172. - P. 207-216.

26. A.D. Zolotarenko, D.V. Shchur, S.I. Zaginaychenko, N.A. Anikin, O.Y. Krivushchenko, V.V. Skorokhod, And. Zolotarenko, Al. Zolotarenko. Discovery of the "Ordering Effect" of the meta-isomer-product of nitration of monosubstituted benzene and its relation to the reactivity of monosubstituted benzenes in reactions of intermolecular donor-acceptor interaction with fullerene C60. // Book of Abstracts of the XIth Int. "Hydrogen material science and chemistry of carbon nanomaterials", Yalta, Crimea, -2009. - P. 606-609 (in Russian).

27. Y.M. Shulga, S.A. Baskakov, A.D. Zolotarenko, E.N. Kabachkov, V.E. Muradyan, D.N. Voylov, V.A. Smirnov, V.M. Martynenko, D.V. Shchur, A.P. Pomytkin. Staining of graphene oxide nanolides and colored polymer compositions on their basis // Journal of Nanosystems, Nanomaterials, Nanotechnologies. - 2013. - Vol. 11. -No. 1.2. - P. 161-171 (in Russian).

28. A.A. Volodin, A.D. Zolotarenko, A.A. Belmesov, E.B. Gerasimova, D.V. Shchur, B.P. Tarasov, S.I. Zaginaychenko, S.V. Doroshenko, An. D. Zolotarenko, Al. D. Zolotarenko. Electroconductive composite materials based on metal oxides and carbon nanostructures // The journal "Nanosestemi, nanomaterials, nanotechnology". - 2014. -Vol.12. -No. 4. -Pp. 705-714 (in Russian).

29. The Great Soviet Encyclopedia. - Moscow: Soviet Encyclopedia. 1969-1978 (in Russian). 